\title{
Infection Source and Epidemiology of Nontuberculous Mycobacterial Lung Disease
}

\author{
Doosoo Jeon, M.D. ${ }^{(10}$ \\ Department of Internal Medicine, Pusan National University Yangsan Hospital, Pusan National University School of Medicine, \\ Yangsan, Korea
}

\begin{abstract}
Nontuberculous mycobacteria (NTM) are ubiquitous organisms that are generally found not only in the natural environment but also in the human engineered environment, including water, soil, and dust. These organisms can form biofilms and can be readily aerosolized because they are hydrophobic owing to the presence of the lipidrich outer membrane. Aerosolization and subsequent inhalation were the major route of NTM lung disease. Water distribution systems and household plumbing are ideal habit for NTM and the main transmission route from natural water to household. NTM have been isolated from drinking water, faucets, pipelines, and water tanks. Studies that used genotyping have shown that NTM isolates from patients are identical to those in the environment, that is, from shower water, showerheads, tap water, and gardening soil. Humans are likely to be exposed to NTM in their homes through simple and daily activities, such as drinking, showering, or gardening. In addition to environmental factors, host factors play an important role in the development of NTM lung disease. The incidence and prevalence of NTM lung disease are increasing worldwide, and this disease is rapidly becoming a major public health problem. NTM lung disease is associated with substantially impaired quality of life, increased morbidity and mortality, and high medical costs. A more comprehensive understanding of the infection source and epidemiology of NTM is essential for the development of new strategies that can prevent and control NTM infection.
\end{abstract}

Keywords: Nontuberculous Mycobacteria; Biofilms; Epidemiology; Lung Diseases

\section{Introduction}

The term nontuberculous mycobacteria (NTM) generally refers to mycobacteria species other than the Mycobacterium tuberculosis complex and M. leprae ${ }^{1,2}$. Although, NTM were

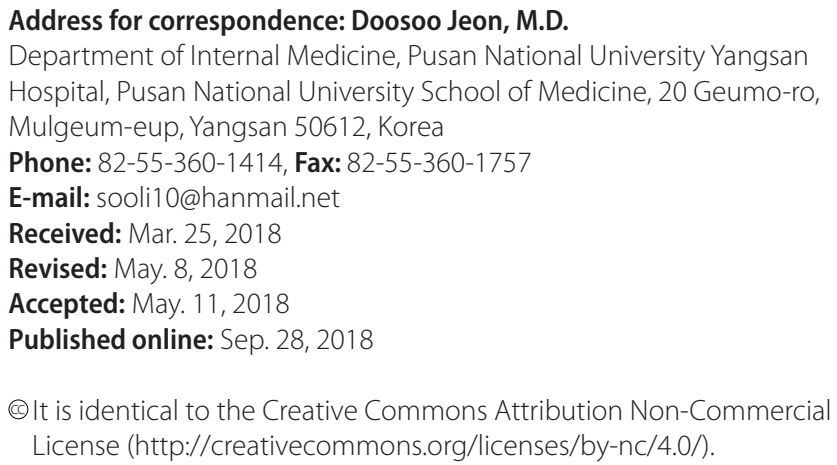
The Korean Academy of Tuberculosis and Respiratory Diseases. first identified in the late 19th century, NTM were not widely recognized as a cause of human disease until the late $1950 \mathrm{~s}^{3}$. They have been called by various names including "atypical mycobacteria," "environmental mycobacteria," and "mycobacteria other than tuberculosis." As these names imply, NTM disease have received less attention than tuberculosis (TB) and were considered as a minor disease.

Currently, NTM, which are evidently different from $M$. tuberculosis, have emerged as important pathogens worldwide $^{4,5}$. The incidence and prevalence of NTM diseases are increasing, and their impact on human health has been a topic of interest. The diagnosis and treatment of NTM lung disease remains challenging for clinicians ${ }^{6}$. Microbiological eradication using the currently available dugs is difficult ${ }^{7}$. Furthermore, microbiological recurrence is common even after a successful treatment, with a substantially high reinfection rate $^{8-10}$. Therefore, to appropriately prevent and treat NTM diseases, the infection sources and epidemiology of NTM infection should be understood. 


\section{Infection Source}

\section{Environmental source of infection}

\section{1) Natural environment}

NTM are naturally occurring environmental pathogens. These organisms have been isolated from natural water, including rivers, lakes, swamps, and streams, as well as soil (Table $1)^{11,12}$. NTM have a lipid-rich outer membrane ${ }^{13}$, which is a key factor in its survival and proliferation in the natural environment $^{11}$. As an effect of the lipid-rich outer membrane, these organisms are resistant to acid ${ }^{14}$, antibiotics ${ }^{15}$, disinfectants ${ }^{16}$, and high temperature ${ }^{17}$. NTM can survive within amoebae ${ }^{18}$. These pathogens are quite hydrophobic due to their lipid-rich outer membrane and prefer to attach to surfaces and subsequently form biofilms ${ }^{19}$. NTM are readily aerosolized from natural water and soils due to its surface hydrophobicity ${ }^{20}$. Naturally occurring aerosolization and subsequent inhalation were the major route of NTM lung disease.

Epidemiology studies have supported the claims that environmental factors could affect the risk for NTM lung disease. In the United States, eight of 55 states were identified as hot spots, with a high incidence of NTM lung disease ${ }^{21}$. The eight states had a higher mean daily potential evapotranspiration levels and percentages covered by surface water and were more likely to have greater copper and sodium levels in the soil $^{21}$. Another study on a registry of patients with cystic fibrosis has reported that high saturated vapor pressure is associated with the increased prevalence of NTM lung disease ${ }^{22}$.

Table 1. Source of nontuberculous mycobacteria

\begin{tabular}{|l|}
\hline Natural environment \\
\hline Natural water in lakes, rivers, streams, and swamps \\
Soils and dust from soils \\
\hline Household environment \\
\hline Household plumbing systems \\
\hline Drinking water and distribution systems \\
\hline Shower heads and faucets \\
\hline Hot tubs, spas, hydrotherapy pools, and footbaths \\
\hline Humidifiers \\
\hline Refrigerator water and ice \\
\hline Garden and potting soils \\
\hline Hospital environment \\
\hline Hospital plumbing systems \\
\hline Hospital water and distribution system \\
\hline Contaminated medical device: heater-cooler devices \\
\hline Filter and ice machines \\
\hline
\end{tabular}

\section{2) Household environment}

NTM are widely distributed in human engineered and household environment. Water distribution systems are thought to be a main transmission route from natural surface water reservoirs to the household. NTM have been isolated from drinking water pipelines ${ }^{23,24}$ and water tanks $\mathrm{s}^{25}$. The number of NTM increases by 2 -fold in a drinking water distribution system, that is, from the treatment plant to the end user ${ }^{26}$. Cell surface hydrophobicity is a major determinant of the survival and proliferation of NTM in the water distribution systems. These organisms can attach to pipe surfaces and form biofilms, which prevents them from being flushed from the water distribution system. Furthermore, NTM are more resistant to common water disinfectants, such as chlorine, than other microorganisms. Therefore, the use of disinfects kills off competitors and selects NTM.

Household and building plumbing systems provide a stable, nutrient-limited, disinfectant-containing habitat that is ideal for NTM growth and persistence. As NTM are relatively resistant to high temperature, these organisms can survive in water heaters and hot water pipes. Households with water heater temperatures $<50^{\circ} \mathrm{C}$ were more likely to yield NTM $(17 / 20$, $85 \%)$ than those with water temperature $>55^{\circ} \mathrm{C}(6 / 15,40 \%)^{27}$. Numerous studies have shown that showerheads and tap water as well as the end points of drinking water distribution systems are the reservoirs of NTM in the household ${ }^{28}$. Studies that used genotyping have shown that NTM isolates from patients are identical to those in the environment, that is, from shower water ${ }^{29,30}$, showerheads ${ }^{31}$, and household tap water ${ }^{32}$.

NTM species have been isolated from house dust ${ }^{33}$ and soils ${ }^{34}$. Dry potting soil is a problem because the soil particles can be aerosolized during gardening, and thus, an individual can inhale these particles. DNA fingerprinting methods have shown that NTM isolates from a patient and those from the patient's dried potting and garden soil were identical ${ }^{34}$.

\section{3) Hospital environment}

NTM are also found in hospital environment. Hospital water distribution system may serve as a reservoir of NTM. These organisms contaminate hospital materials and can cause nosocomial outbreaks and pseudo-outbreaks ${ }^{35}$. Recently, several outbreaks due to $M$. chimaera have occurred from heatercooler devices used during open-heart surgery ${ }^{36,37}$.

\section{Transmission}

NTM are generally acquired from the environment via ingestion, inhalation, and dermal contact ${ }^{1,2}$. These organisms are everywhere in the human environment and can be readily aerosolized. NTM in household plumbing systems are readily aerosolized from taps, showerheads, and hot tubs. Home humidifiers filled with household water could be a potential generator of a high number of NTM in aerosols ${ }^{12}$. Use of indoor 
swimming pools has been associated with NTM lung disease among individuals with cystic fibrosis ${ }^{38}$. Dusts generated during potting of plants or gardening are also likely sources of NTM infection. Humans are likely to be exposed to NTM in their homes through simple daily activities, such as drinking, showering, or gardening ${ }^{39}$. The most common routes for pulmonary NTM infection involve the inhalation of aerosols generated by hot tubs and showerheads. Indeed, the global increase in NTM infections may reflect the use of showers rather than bathing ${ }^{40}$.

\section{1) Human to human transmission}

Traditionally, it was believed that human-to-human NTM transmission is not possible. Whole genome sequencing, a new molecular technique, has provided the first genetic evidence of human-to-human transmission of $M$. abscessus complex among patients with cystic fibrosis ${ }^{41,42}$. Bryant et al. ${ }^{42}$ have performed a whole genome sequencing analysis of 1,080 clinical isolates of $M$. abscessus complex obtained from 517 patients from cystic fibrosis centers in seven countries. Results have shown that most $M$. abscessus complex infections were acquired via human-to-human transmission, potentially via fomites and aerosols.

\section{Preventive measure}

Strategies that are effective in preventing NTM lung disease are still limited. Vaccines and prophylaxis medications are not available. Unlike TB, preventive therapy is only recommended in patients with advanced human immunodeficiency virus (HIV) disease. A more comprehensive understanding of NTM transmission can help in establishing targeted prophylactic measures. Some preventive measures are recommended to avoid NTM exposure and reduce the number of NTM in the household ${ }^{12}$. Although the efficacy of these recommendations has not yet been validated via clinical trials, these are still helpful for vulnerable individuals with a high risk for infection.
Preventive measures recommended by experts are the following ${ }^{12}$ : (1) raise hot water temperature to $55^{\circ} \mathrm{C}$; (2) use bacteriologic filters (pore size $<0.45 \mathrm{~mm}$ ) on taps and showerheads; (3) utilize well water rather than piped utility supply; (4) clean and disinfect showerheads regularly to remove the biofilm; (5) use showerheads with large holes to reduce mist formation; (6) avoid spas and hot tubs or any water with an aerator; (7) increase bathroom exhaust rate; (8) boil drinking water for 10 minutes to kill NTM; (9) wear mask when gardening; and (10) moisten garden and potting soils.

\section{Epidemiology}

\section{Incidence and prevalence of NTM}

The identification of the epidemiology of NTM lung disease has been challenging because reporting of cases is not mandatory in most countries. Furthermore, diagnosis is difficult because simple isolation of the organism does not necessarily indicate the actual lung disease. Various epidemiological methodologies have been used, including surveillance, population-based studies, analysis of large linked datasets, studies that used laboratory-based convenience samples, and combinations of these approaches ${ }^{43}$.

Numerous studies have shown that the incidence and prevalence of NTM lung disease are increasing worldwide ${ }^{44}$. Population-based data from the United States ${ }^{45}$, Canada ${ }^{46}$, the United Kingdom ${ }^{47}$, and Australia ${ }^{48}$ have shown that the prevalence of NTM lung disease has been increasing. Large tertiary care facility-based studies in East Asian countries, including $\operatorname{Japan}^{49}$, Taiwan ${ }^{50}$, and South Korea ${ }^{51,52}$, have also suggested an increasing prevalence of NTM lung disease. In South Korea, no population-based study on the epidemiology of NTM lung disease was conducted. Most studies were conducted in a single institution using laboratory-based convenience samples. Those studies have consistently shown that the proportion

Table 2. Changes in the proportions of nontuberculous mycobacteria among mycobacterial isolates from clinical respiratory specimens in South Korea

\begin{tabular}{|lllcr|}
\hline \multicolumn{1}{|c}{ Study } & \multicolumn{1}{c}{ Hospital } & Study period & \multicolumn{2}{c|}{ Proportion of nontuberculous mycobacteria } \\
\cline { 3 - 5 } & & Start of study period & End of study period \\
\hline Park et al. $(2010)^{53}$ & Seoul National University Hospital & $2002-2008$ & $427 / 1,921(22 \%)$ & $781 / 1,701(46 \%)$ \\
\hline Lee et al. $(2012)^{54}$ & Severance Hospital & $2006-2010$ & $268 / 1,041(26 \%)$ & $970 / 2,064(47 \%)$ \\
Yoo et al. $(2012)^{55}$ & Asan Medical Center & $2002-2010$ & $403 / 1,921(21 \%)$ & $1,530 / 2,648(59 \%)$ \\
\hline Koh et al. $(2013)^{56}$ & Samsung Medical Center & $2001-2011$ & $548 / 1,283(43 \%)$ & $3,341 / 4,800(70 \%)$ \\
\hline Kim and Rheem $(2013)^{57}$ & Dankook University Hospital & $2005-2011$ & $26 \%$ & $44 \%$ \\
\hline Lee et al. $(2014)^{58}$ & Ulsan University Hospital & $2010-2013$ & $25 \%$ & $38 \%$ \\
\hline Kim et al. $(2017)^{59, *}$ & Pusan National University Hospital & $2009-2015$ & $24.8 \%$ & $44.8 \%$ \\
\hline
\end{tabular}

*This study included both respiratory and non-respiratory specimens. 
of NTM among positive mycobacterial cultures is increasing (Table 2) $)^{53-59}$. In a 10-year observational study ${ }^{56}$, the proportion of NTM among all positive mycobacterial cultures increased from $43 \%$ in 2001 to $70 \%$ in 2011 . Furthermore, the recovery rate of NTM isolates from acid-fast bacilli smear-positive specimens increased from 9\% in 2001 to $64 \%$ in 2011 . This finding has suggested that early differentiation between pulmonary TB and NTM lung disease has become a clinically important issue in South Korea due to the increasing incidence and prevalence of NTM lung disease. Recently, Yoon et al. ${ }^{60}$ have reported a nationwide increasing trend in the prevalence of NTM disease from 2009 to 2016 in South Korea based on the

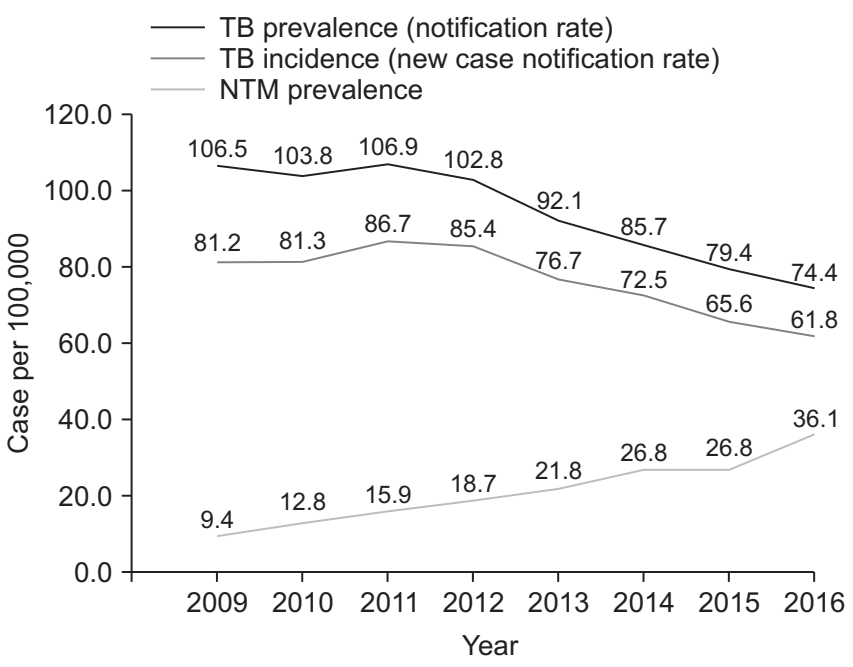

Figure 1. Trend in the prevalence of tuberculosis (TB) and nontuberculous disease from 2009 to 2016 in South Korea. NTM: nontuberculous mycobacteria. Adopted from Yoon et al. BMC infect Dis 2017;17:432, according to Creative Commons license ${ }^{60}$. claims data of the Health Insurance Review and Assessment Service (Figure 1). Interestingly, the increase in the proportion of NTM lung disease may be associated with a simultaneous decrease in the incidence of TB in most countries ${ }^{61}$, including South Korea ${ }^{60}$.

\section{Species distribution}

The distribution of NTM species varies by region and country. This geographical diversity can provide important clues to identify factors associated with the acquisition of NTM infection, such as geographic factors, population density, or host factors. In 2008, the NTM-Network European Trials Group provided species identification data for 20,182 patients from 62 laboratories in 30 countries $^{62}$. This study has shown that the Mycobacterium avium complex (MAC) predominated in most countries. However, there were important differences in the geographical distribution of $M$. xenopi, $M$. kansasii, and other rapid-growing mycobacteria. M. xenopi and M. malmoense were extremely rare in East Asia. However, they are predominantly found in Europe.

In South Korea, the MAC is the most common organism causing NTM lung disease (Table 3$)^{53,54,58,60,63-65}$, which is similar to other countries. M. abscessus complex is the second most common organism, whereas $M$. kansasii does not commonly cause the disease. However, $M$. kansasii was the second most common NTM species in Ulsan ${ }^{58}$.

\section{Risk factor}

Exposure to NTM is quite common. However, NTM disease is relatively rare. This observation suggests that host susceptibility likely plays a key role in the development of NTM lung disease. Patients who develop NTM lung disease usually have

Table 3. Etiologic species of nontuberculous mycobacterial lung disease in South Korea

\begin{tabular}{|c|c|c|c|c|c|c|c|}
\hline & $\begin{array}{l}\text { Koh et al. } \\
(2006)^{63}\end{array}$ & $\begin{array}{c}\text { Park et al. } \\
(2010)^{53}\end{array}$ & $\begin{array}{l}\text { Lee et al. } \\
(2012)^{54}\end{array}$ & $\begin{array}{l}\text { Jang et al. } \\
(2014)^{64}\end{array}$ & $\begin{array}{l}\text { Lee et al. } \\
(2014)^{58}\end{array}$ & $\begin{array}{l}\text { Kim et al. } \\
(2014)^{65}\end{array}$ & $\begin{array}{l}\text { Yoon et al. } \\
(2017)^{60}\end{array}$ \\
\hline Study period & $2002-2003$ & $2002-2008$ & $2006-2010$ & 2012 & $2010-2013$ & $2007-2011$ & 2011-2016 \\
\hline Mycobacterium avium complex & $94(48)$ & NA (63) & $263(76)$ & $73(66)$ & $132(54)$ & $61(68)$ & $29(45)$ \\
\hline M. avium & 38 & NA & 141 & 32 & 39 & 42 & 13 \\
\hline M. abscessus & NA & NA & NA & 21 & NA & 11 & NA \\
\hline M. massiliense & NA & NA & NA & 11 & NA & 4 & NA \\
\hline M. kansasii & $7(4)$ & NA & $7(2)$ & $1(1)$ & $80(33)$ & $1(1)$ & $4(6)$ \\
\hline Others & $30(15)$ & NA (10) & $12(3)$ & $5(5)$ & $11(4)$ & $13(14)$ & $4(6)$ \\
\hline
\end{tabular}

Values are presented as number (\%).

NA: not available. 
some degree of host impairment that make them vulnerable to these infections. NTM lung disease is more prevalent in patients with structural lung disease, such as cystic fibrosis, non-cystic fibrosis bronchiectasis, primary ciliary dyskinesia, chronic obstructive pulmonary disease (COPD), previous TB, and pneumoconiosis ${ }^{66}$. An immunosuppressed status, which is related to HIV infection, transplantation, or the use of tumor necrosis factor $\alpha$ inhibitor, is also associated with NTM disease $^{66}$.

However, patients can develop NTM lung disease without any obvious underlying cause. These patients are typically postmenopausal women who have a unique body morphotype $^{67,68}$. Recently, a whole-exome sequencing study has begun to identify genetic predispositions for those patients and found an increased prevalence of genetic mutations that control the function of the immune system, ciliary body, and connective tissue $^{69}$. This suggests that NTM lung disease is a multigenic disease, which is characterized by a combination of variants across gene categories and environmental exposures that increase susceptibility to infection.

\section{Impact on public health}

The impact of NTM infection on public health has been underestimated. Generally, NTM have been considered to have a low pathogenicity, and it was believed that these organisms cannot be transmitted from person to person. However, NTM lung disease is associated with a substantially impaired quality of life ${ }^{70}$, increased morbidity and mortality ${ }^{71}$, and high medical costs ${ }^{43}$. Huang et al. ${ }^{72}$ have shown that patients with COPD who have NTM isolates had a greater decline in lung function and more frequent exacerbation than those with no isolate. Park et al. ${ }^{73}$ have shown that treatment failure was associated with a substantial decline in lung function in individuals with NTM lung disease. A recent study in Germany have revealed that a higher mortality, direct costs, and indirect costs were observed among patients with NTM lung disease than in matched controls ${ }^{74}$. Considering the increasing burden of NTM lung disease globally, this disease may soon become a significant health and economic burden.

\section{Conclusion}

NTM are generally found not only in the natural but also in the human engineered environment. Remarkable changes in the human environment and lifestyle habits were observed during the past several decades. These changes have made humans more comfortable but also resulted in a more favorable environment for NTM growth. In addition, with the development of medicine, an aging population with multiple comorbidities who are vulnerable to NTM infection is growing rapidly. As a result, the incidence and prevalence of NTM lung disease are increasing worldwide, and this disease is rapidly becoming a major public health problem. NTM lung disease is more difficult to treat and prevent than TB. The elimination of NTM from environmental sources and the destruction of the transmission route are critical issues that must be urgently addressed. Further comprehensive works to investigate the source, transmission route, and epidemiology of NTM are needed to develop new strategies that can prevent and control NTM infection.

\section{Conflicts of Interest}

No potential conflict of interest relevant to this article was reported.

\section{References}

1. Griffith DE, Aksamit T, Brown-Elliott BA, Catanzaro A, Daley C, Gordin F, et al. An official ATS/IDSA statement: diagnosis, treatment, and prevention of nontuberculous mycobacterial diseases. Am J Respir Crit Care Med 2007;175:367-416.

2. Haworth CS, Banks J, Capstick T, Fisher AJ, Gorsuch T, Laurenson IF, et al. British Thoracic Society guidelines for the management of non-tuberculous mycobacterial pulmonary disease (NTM-PD). Thorax 2017;72(Suppl 2):ii1-64.

3. Runyon EH. Anonymous mycobacteria in pulmonary disease. Med Clin North Am 1959;43:273-90.

4. Griffith DE, Aksamit TR. Understanding nontuberculous mycobacterial lung disease: it's been a long time coming. F1000Res 2016;5:2797.

5. Koh WJ. Nontuberculous mycobacteria: overview. Microbiol Spectr 2017 Jan [Epub]. https://doi.org/10.1128/microbiolspec.TNMI7-0024-2016.

6. Ryu YJ, Koh WJ, Daley CL. Diagnosis and treatment of nontuberculous mycobacterial lung disease: clinicians' perspectives. Tuberc Respir Dis 2016;79:74-84.

7. Stout JE, Koh WJ, Yew WW. Update on pulmonary disease due to non-tuberculous mycobacteria. Int J Infect Dis 2016;45:123-34.

8. Wallace RJ Jr, Zhang Y, Brown-Elliott BA, Yakrus MA, Wilson RW, Mann L, et al. Repeat positive cultures in Mycobacterium intracellulare lung disease after macrolide therapy represent new infections in patients with nodular bronchiectasis. J Infect Dis 2002;186:266-73.

9. Wallace RJ Jr, Brown-Elliott BA, McNulty S, Philley JV, Killingley J, Wilson RW, et al. Macrolide/Azalide therapy for nodular/bronchiectatic mycobacterium avium complex lung disease. Chest 2014;146:276-82.

10. Koh WJ, Moon SM, Kim SY, Woo MA, Kim S, Jhun BW, et al. Outcomes of Mycobacterium avium complex lung disease based on clinical phenotype. Eur Respir J 2017;50:1602503. 
11. Falkinham JO 3rd. Surrounded by mycobacteria: nontuberculous mycobacteria in the human environment. J Appl Microbiol 2009;107:356-67.

12. Falkinham JO 3rd. Environmental sources of nontuberculous mycobacteria. Clin Chest Med 2015;36:35-41.

13. Brennan PJ, Nikaido H. The envelope of mycobacteria. Annu Rev Biochem 1995;64:29-63.

14. Bodmer T, Miltner E, Bermudez LE. Mycobacterium avium resists exposure to the acidic conditions of the stomach. FEMS Microbiol Lett 2000;182:45-9.

15. Rastogi N, Frehel C, Ryter A, Ohayon H, Lesourd M, David HL. Multiple drug resistance in Mycobacterium avium: is the wall architecture responsible for exclusion of antimicrobial agents? Antimicrob Agents Chemother 1981;20:666-77.

16. Taylor RH, Falkinham JO 3rd, Norton CD, LeChevallier MW. Chlorine, chloramine, chlorine dioxide, and ozone susceptibility of Mycobacterium avium. Appl Environ Microbiol 2000;66:1702-5.

17. Schulze-Robbecke R, Buchholtz K. Heat susceptibility of aquatic mycobacteria. Appl Environ Microbiol 1992;58:186973.

18. Cirillo JD, Falkow S, Tompkins LS, Bermudez LE. Interaction of Mycobacterium avium with environmental amoebae enhances virulence. Infect Immun 1997;65:3759-67.

19. Faria S, Joao I, Jordao L. General overview on nontuberculous mycobacteria, biofilms, and human infection. J Pathog 2015;2015:809014.

20. Parker BC, Ford MA, Gruft H, Falkinham JO 3rd. Epidemiology of infection by nontuberculous mycobacteria. IV. Preferential aerosolization of Mycobacterium intracellulare from natural waters. Am Rev Respir Dis 1983;128:652-6.

21. Adjemian J, Olivier KN, Seitz AE, Falkinham JO 3rd, Holland SM, Prevots DR. Spatial clusters of nontuberculous mycobacterial lung disease in the United States. Am J Respir Crit Care Med 2012;186:553-8.

22. Adjemian J, Olivier KN, Prevots DR. Nontuberculous mycobacteria among patients with cystic fibrosis in the United States: screening practices and environmental risk. Am J Respir Crit Care Med 2014;190:581-6.

23. Nishiuchi Y, Iwamoto T, Maruyama F. Infection sources of a common non-tuberculous mycobacterial pathogen, Mycobacterium avium complex. Front Med (Lausanne) 2017;4:27.

24. Thomson R, Tolson C, Sidjabat H, Huygens F, Hargreaves M. Mycobacterium abscessus isolated from municipal water: a potential source of human infection. BMC Infect Dis 2013;13:241.

25. Torvinen E, Suomalainen S, Lehtola MJ, Miettinen IT, Zacheus $\mathrm{O}$, Paulin L, et al. Mycobacteria in water and loose deposits of drinking water distribution systems in Finland. Appl Environ Microbiol 2004;70:1973-81.

26. Tuffley RE, Holbeche JD. Isolation of the Mycobacterium avium-M. intracellulare-M. scrofulaceum complex from tank water in Queensland, Australia. Appl Environ Microbiol
1980;39:48-53.

27. Falkinham JO 3rd, Norton CD, LeChevallier MW. Factors influencing numbers of Mycobacterium avium, Mycobacterium intracellulare, and other mycobacteria in drinking water distribution systems. Appl Environ Microbiol 2001;67:122531.

28. Falkinham JO 3rd. Nontuberculous mycobacteria from household plumbing of patients with nontuberculous mycobacteria disease. Emerg Infect Dis 2011;17:419-24.

29. Thomson R, Tolson C, Carter R, Coulter C, Huygens F, Hargreaves $\mathrm{M}$. Isolation of nontuberculous mycobacteria (NTM) from household water and shower aerosols in patients with pulmonary disease caused by NTM. J Clin Microbiol 2013;51:3006-11.

30. Falkinham JO 3rd, Iseman MD, de Haas P, van Soolingen D. Mycobacterium avium in a shower linked to pulmonary disease. J Water Health 2008;6:209-13.

31. Feazel LM, Baumgartner LK, Peterson KL, Frank DN, Harris JK, Pace NR. Opportunistic pathogens enriched in showerhead biofilms. Proc Natl Acad Sci U S A 2009;106:16393-9.

32. von Reyn CF, Maslow JN, Barber TW, Falkinham JO 3rd, Arbeit RD. Persistent colonisation of potable water as a source of Mycobacterium avium infection in AIDS. Lancet 1994;343:1137-41.

33. Reznikov M, Dawson DJ. Serological investigation of strains of Mycobacterium intracellulare ("battey" bacillus) isolated from house-dusts. Med J Aust 1971;1:682-3.

34. De Groote MA, Pace NR, Fulton K, Falkinham JO 3rd. Relationships between Mycobacterium isolates from patients with pulmonary mycobacterial infection and potting soils. Appl Environ Microbiol 2006;72:7602-6.

35. Sood G, Parrish N. Outbreaks of nontuberculous mycobacteria. Curr Opin Infect Dis 2017;30:404-9.

36. Allen KB, Yuh DD, Schwartz SB, Lange RA, Hopkins R, Bauer K, et al. Nontuberculous Mycobacterium infections associated with heater-cooler devices. Ann Thorac Surg 2017;104:1237-42.

37. Williamson D, Howden B, Stinear T. Mycobacterium chimaera spread from heating and cooling units in heart surgery. $\mathrm{N}$ Engl J Med 2017;376:600-2.

38. Prevots DR, Adjemian J, Fernandez AG, Knowles MR, Olivier KN. Environmental risks for nontuberculous mycobacteria: individual exposures and climatic factors in the cystic fibrosis population. Ann Am Thorac Soc 2014;1 1:1032-8.

39. Halstrom S, Price P, Thomson R. Review: environmental mycobacteria as a cause of human infection. Int J Mycobacteriol 2015;4:81-91.

40. O'Brien DP, Currie BJ, Krause VL. Nontuberculous mycobacterial disease in northern Australia: a case series and review of the literature. Clin Infect Dis 2000;31:958-67.

41. Bryant JM, Grogono DM, Greaves D, Foweraker J, Roddick I, Inns $\mathrm{T}$, et al. Whole-genome sequencing to identify transmission of Mycobacterium abscessus between patients with cystic 
fibrosis: a retrospective cohort study. Lancet 2013;381:155160.

42. Bryant JM, Grogono DM, Rodriguez-Rincon D, Everall I, Brown KP, Moreno P, et al. Emergence and spread of a human-transmissible multidrug-resistant nontuberculous mycobacterium. Science 2016;354:751-7.

43. Prevots DR, Loddenkemper R, Sotgiu G, Migliori GB. Nontuberculous mycobacterial pulmonary disease: an increasing burden with substantial costs. Eur Respir J 2017;49:1700374.

44. Prevots DR, Marras TK. Epidemiology of human pulmonary infection with nontuberculous mycobacteria: a review. Clin Chest Med 2015;36:13-34.

45. Adjemian J, Olivier KN, Seitz AE, Holland SM, Prevots DR. Prevalence of nontuberculous mycobacterial lung disease in U.S. Medicare beneficiaries. Am J Respir Crit Care Med 2012;185:881-6.

46. Marras TK, Mendelson D, Marchand-Austin A, May K, Jamieson FB. Pulmonary nontuberculous mycobacterial disease, Ontario, Canada, 1998-2010. Emerg Infect Dis 2013;19:188991.

47. Moore JE, Kruijshaar ME, Ormerod LP, Drobniewski F, Abubakar I. Increasing reports of non-tuberculous mycobacteria in England, Wales and Northern Ireland, 1995-2006. BMC Public Health 2010;10:612.

48. Thomson RM; NTM working group at Queensland TB Control Centre and Queensland Mycobacterial Reference Laboratory. Changing epidemiology of pulmonary nontuberculous mycobacteria infections. Emerg Infect Dis 2010;16:157683.

49. Ide S, Nakamura S, Yamamoto Y, Kohno Y, Fukuda Y, Ikeda H, et al. Epidemiology and clinical features of pulmonary nontuberculous mycobacteriosis in Nagasaki, Japan. PLoS One 2015;10:e128304.

50. Lai CC, Tan CK, Chou CH, Hsu HL, Liao CH, Huang YT, et al. Increasing incidence of nontuberculous mycobacteria, Taiwan, 2000-2008. Emerg Infect Dis 2010;16:294-6.

51. Kwon YS, Koh WJ. Diagnosis and treatment of nontuberculous mycobacterial lung disease. J Korean Med Sci 2016;31:649-59.

52. Ko RE, Moon SM, Ahn S, Jhun BW, Jeon K, Kwon OJ, et al. Changing epidemiology of nontuberculous mycobacterial lung diseases in a tertiary referral hospital in Korea between 2001 and 2015. J Korean Med Sci 2018;33:e65.

53. Park YS, Lee CH, Lee SM, Yang SC, Yoo CG, Kim YW, et al. Rapid increase of non-tuberculous mycobacterial lung diseases at a tertiary referral hospital in South Korea. Int J Tuberc Lung Dis 2010;14:1069-71.

54. Lee SK, Lee EJ, Kim SK, Chang J, Jeong SH, Kang YA. Changing epidemiology of nontuberculous mycobacterial lung disease in South Korea. Scand J Infect Dis 2012;44:733-8.

55. Yoo JW, Jo KW, Kim MN, Lee SD, Kim WS, Kim DS, et al. Increasing trend of isolation of non-tuberculous mycobacteria in a tertiary university hospital in South Korea. Tuberc Respir
Dis 2012;72:409-15.

56. Koh WJ, Chang B, Jeong BH, Jeon K, Kim SY, Lee NY, et al. Increasing recovery of nontuberculous mycobacteria from respiratory specimens over a 10 -year period in a tertiary referral hospital in South Korea. Tuberc Respir Dis 2013;75:199204.

57. Kim JK, Rheem I. Identification and distribution of nontuberculous mycobacteria from 2005 to 2011 in cheonan, Korea. Tuberc Respir Dis 2013;74:215-21.

58. Lee MY, Lee T, Kim MH, Byun SS, Ko MK, Hong JM, et al. Regional differences of nontuberculous mycobacteria species in Ulsan, Korea. J Thorac Dis 2014;6:965-70.

59. Kim N, Yi J, Chang CL. Recovery rates of non-tuberculous mycobacteria from clinical specimens are increasing in Korean tertiary-care hospitals. J Korean Med Sci 2017;32:1263-7.

60. Yoon HJ, Choi HY, Ki M. Nontuberculosis mycobacterial infections at a specialized tuberculosis treatment centre in the Republic of Korea. BMC Infect Dis 2017;17:432.

61. Brode SK, Daley CL, Marras TK. The epidemiologic relationship between tuberculosis and non-tuberculous mycobacterial disease: a systematic review. Int J Tuberc Lung Dis 2014;18:1370-7.

62. Hoefsloot W, van Ingen J, Andrejak C, Angeby K, Bauriaud R, Bemer P, et al. The geographic diversity of nontuberculous mycobacteria isolated from pulmonary samples: an NTMNET collaborative study. Eur Respir J 2013;42:1604-13.

63. Koh WJ, Kwon OJ, Jeon K, Kim TS, Lee KS, Park YK, et al. Clinical significance of nontuberculous mycobacteria isolated from respiratory specimens in Korea. Chest 2006;129:341-8.

64. Jang MA, Koh WJ, Huh HJ, Kim SY, Jeon K, Ki CS, et al. Distribution of nontuberculous mycobacteria by multigene sequence-based typing and clinical significance of isolated strains. J Clin Microbiol 2014;52:1207-12.

65. Kim HS, Lee Y, Lee S, Kim YA, Sun YK. Recent trends in clinically significant nontuberculous mycobacteria isolates at a Korean general hospital. Ann Lab Med 2014;34:56-9.

66. Honda JR, Knight V, Chan ED. Pathogenesis and risk factors for nontuberculous mycobacterial lung disease. Clin Chest Med 2015;36:1-11.

67. Kartalija M, Ovrutsky AR, Bryan CL, Pott GB, Fantuzzi G, Thomas J, et al. Patients with nontuberculous mycobacterial lung disease exhibit unique body and immune phenotypes. Am J Respir Crit Care Med 2013;187:197-205.

68. Kim RD, Greenberg DE, Ehrmantraut ME, Guide SV, Ding L, Shea Y, et al. Pulmonary nontuberculous mycobacterial disease: prospective study of a distinct preexisting syndrome. Am J Respir Crit Care Med 2008;178:1066-74.

69. Szymanski EP, Leung JM, Fowler CJ, Haney C, Hsu AP, Chen F, et al. Pulmonary nontuberculous mycobacterial infection: a multisystem, multigenic disease. Am J Respir Crit Care Med 2015;192:618-28

70. Yeung MW, Khoo E, Brode SK, Jamieson FB, Kamiya H, Kwong JC, et al. Health-related quality of life, comorbidities 
and mortality in pulmonary nontuberculous mycobacterial infections: a systematic review. Respirology 2016;21:1015-25.

71. Novosad SA, Henkle E, Schafer S, Hedberg K, Ku J, Siegel SA, et al. Mortality after respiratory isolation of nontuberculous mycobacteria: a comparison of patients who did and did not meet disease criteria. Ann Am Thorac Soc 2017;14:1112-9.

72. Huang CT, Tsai YJ, Wu HD, Wang JY, Yu CJ, Lee LN, et al. Impact of non-tuberculous mycobacteria on pulmonary func- tion decline in chronic obstructive pulmonary disease. Int J Tuberc Lung Dis 2012;16:539-45.

73. Park HY, Jeong BH, Chon HR, Jeon K, Daley CL, Koh WJ. Lung function decline according to clinical course in nontuberculous mycobacterial lung disease. Chest 2016;150:1222-32.

74. Diel R, Jacob J, Lampenius N, Loebinger M, Nienhaus A, Rabe $\mathrm{KF}$, et al. Burden of non-tuberculous mycobacterial pulmonary disease in Germany. Eur Respir J 2017;49:1602109. 